\title{
ANGIOGRAFIA CEREBRAL TRANS-OPERATÓRIA
}

\author{
SÉRgIo RAUPP * \\ SOLON TERUCHKIN ** \\ José Carrasco VIDAURRE **
}

Revisões e estudos críticos de nossa casuística, no que se refere a angiomas cerebrais, nos levaram a concluir pela necessidade da angiografia trans-operatória para evitar secçōes parciais e para facilitar a localização trans-operatória de pequenas fístulas. Se concebido inicialmente como elemento para avaliação do sucesso cirúrgico (Fig. $2 \mathrm{C}$ ), o método tem também servido como subsídio para orientação e delimitação precisa da patologia (Fig. 2 B).

Os resultados do emprêgo sistemático dêste procedimento têm sido apresentados desde 1964 nos congressos brasileiros da especialidade 1, 2, 4, porém a publicação a fazemos sòmente agora, após casuística mais extensa (quadro 1). Em 1966 outro autor ${ }^{3}$ relatou experiência análoga à qual foi levado por idênticos motivos.

Até o momento foram tratados no Instituto de Neurocirurgia de Pôrto Alegre 7 pacientes com angiomas cerebrais, nos quais foram feitas 8 inter-
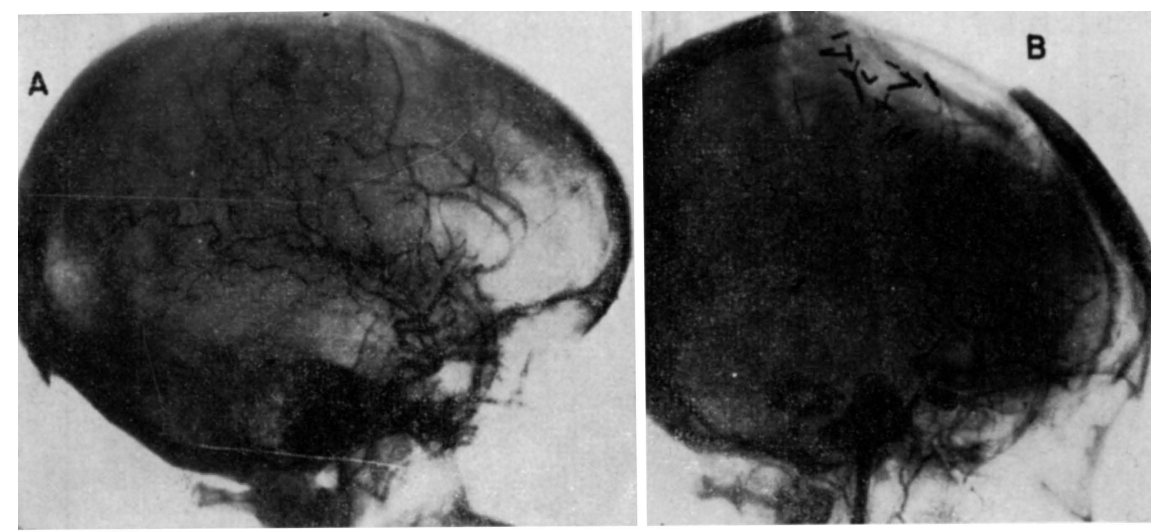

Fig. 1 - Angioma artério-venoso parietal com hematoma. Em A, angiografia pré-operatória. Em $B$, angiografia trans-operatória, estando o crânio em posição assimétrica.

Do Instituto de Neurocirurgia de Pôrto Alegre (Prof. Elyseu Paglioli): * Neuro-radiologista; ** Residentes. 


\begin{tabular}{|c|c|c|c|c|c|c|c|}
\hline Casos & Idade & Sexo & $\begin{array}{c}\text { Exame } \\
\text { pré-operatório }\end{array}$ & $\begin{array}{l}\text { Localizacão } \\
\text { anatômica }\end{array}$ & $\begin{array}{c}\text { Aferências e eferências } \\
\text { vasculares }\end{array}$ & $\begin{array}{l}\text { Técnica } \\
\text { cirúrgica }\end{array}$ & Resultado \\
\hline 1 & 15 & $\mathbf{F}$ & $\begin{array}{l}\text { A. carótida bi- } \\
\text { lateral e verte- } \\
\text { bral }\end{array}$ & $\begin{array}{l}\text { Têrço posterior di- } \\
\text { reito do corpo ca- } \\
\text { loso }\end{array}$ & $\begin{array}{l}\text { A. pericalosas anterior e pos- } \\
\text { terior drenando para a veia } \\
\text { de Galeno }\end{array}$ & Exérese total & Curado \\
\hline 2 & 40 & M & $\begin{array}{l}\text { A. carótida bi- } \\
\text { lateral }\end{array}$ & $\begin{array}{l}\text { Parietal, para-me- } \\
\text { diano direito }\end{array}$ & $\begin{array}{l}\text { A. silviana e pericalosa di- } \\
\text { reitas drenando para o seio } \\
\text { longitudinal superior e veia } \\
\text { cerebral interna. }\end{array}$ & Exérese total & Curado \\
\hline 3 & 19 & M & $\begin{array}{l}\text { A. carótida di- } \\
\text { reita e verte- } \\
\text { bral }\end{array}$ & $\begin{array}{l}\text { Têmporo-occipital } \\
\text { direito }\end{array}$ & $\begin{array}{l}\text { A. silviana e cerebral poste- } \\
\text { rior drenando para o seio } \\
\text { lateral direiot }\end{array}$ & Exérese total & Curado \\
\hline 4 & 25 & $F$ & $\begin{array}{l}\text { A. carótida di- } \\
\text { reita }\end{array}$ & $\begin{array}{l}\text { Fronto-parietal di- } \\
\text { reito }\end{array}$ & $\begin{array}{l}\text { A. caloso marginal direita } \\
\text { drenando para a veia cere- } \\
\text { bral interna }\end{array}$ & $\begin{array}{l}1.9 \text { operacão: } \\
\text { Exérese parcial } \\
2 . q \text { operação: } \\
\text { Exérese total }\end{array}$ & Obito \\
\hline 5 & 35 & M & $\begin{array}{l}\text { A. carótida es- } \\
\text { querda }\end{array}$ & $\begin{array}{l}\text { Fronto-lateral es- } \\
\text { querdo }\end{array}$ & $\begin{array}{l}\text { A. frontais ascendentes (sil- } \\
\text { viana) drenando para o seio } \\
\text { longitudinal superior }\end{array}$ & Exérese total & Curado \\
\hline 6 & 37 & $\mathbf{M}$ & $\begin{array}{l}\text { A. carótida bi- } \\
\text { lateral }\end{array}$ & $\begin{array}{l}\text { Sub-frontal esquer- } \\
\text { do }\end{array}$ & $\begin{array}{l}\text { A. pericalosa drenando para } \\
\text { o seio longitudinal superior }\end{array}$ & Exérese total & Curado \\
\hline 7 & 40 & $F$ & $\begin{array}{l}\text { A. carótida bi- } \\
\text { lateral }\end{array}$ & $\begin{array}{l}\text { Fronto-parietal di- } \\
\text { reito }\end{array}$ & $\begin{array}{l}\text { A. pericalosa e silviana dre- } \\
\text { nando para o seio longitu- } \\
\text { dinal superior }\end{array}$ & Exérese total & Curado \\
\hline
\end{tabular}


venções cirúrgicas, tôdas com angiografia trans-operatória, não surgindo qualquer dificuldade técnica na realização dêste procedimento.

No quadro 1 estão resumidos os itens mais importantes da casuística.

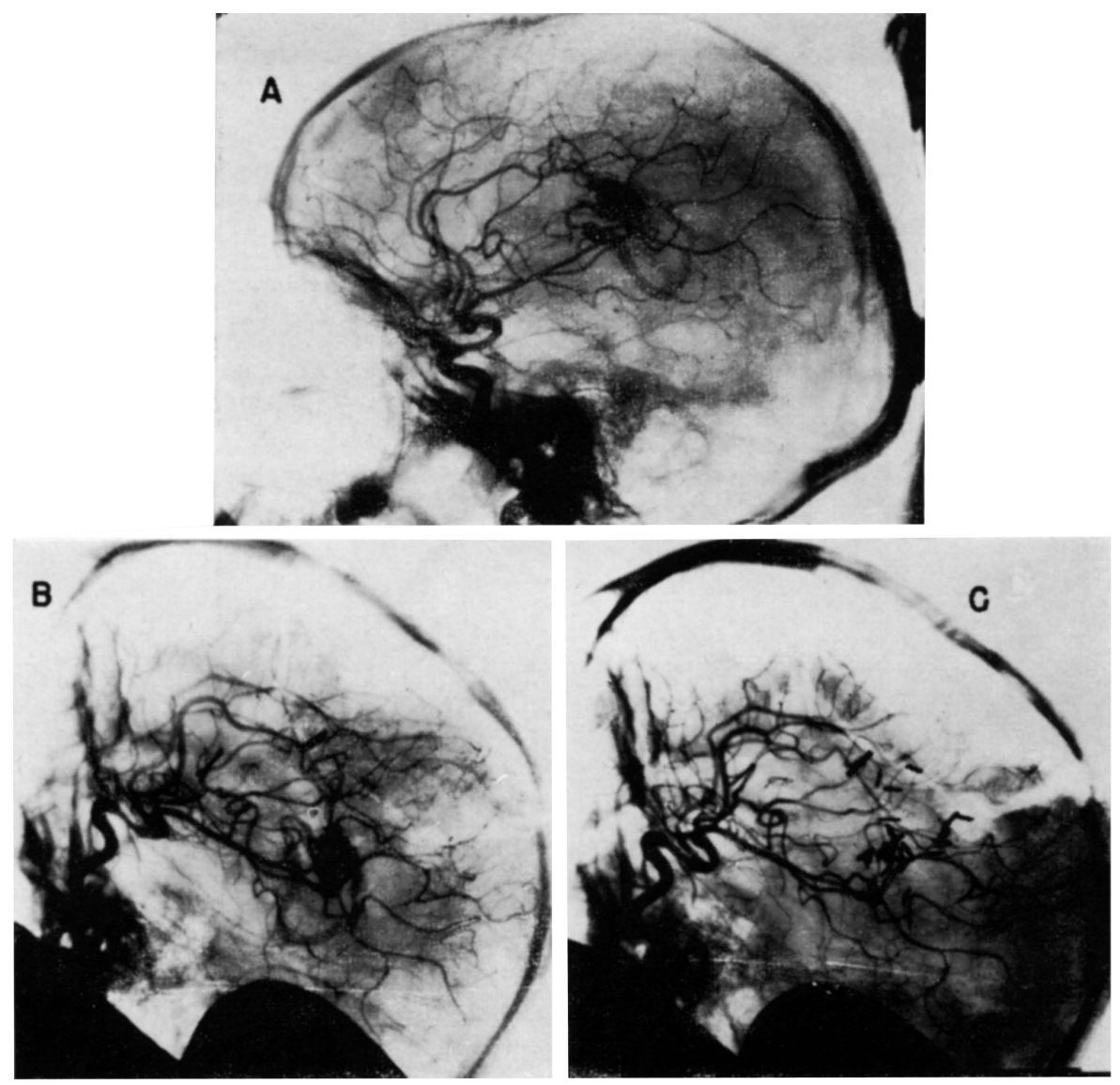

Fig. 2 - Angioma caloso posterior. Em A, angiografia pré-operatória. Em $B$ $e \quad C$, angiografias trans-operatórias: clip de localização $e$ orientação $(B) \quad e$ angiografia pós-ressecção (C).

The author recommends the use of angiography during operations for the treatment of cerebral angiomata, the procedure helping the location of fistulae with little dimensions and securing better surgical results. 
Seven cases of intracranial arteriovenous congenital fistulae are reported in which the neurosurgical procedure was facilitated by transoperatory angiography. There wern't technic difficulties in any occasion.

\section{REFERENCIAS}

1. DAHNE, J. \& RAUPP, S. - Tratamento cirürgico das malformações artériovenosas do encéfalo. Atas do $\mathrm{V}$ Congresso da Sociedade Brasileira de Neurocirurgia, Belo Horizonte, 1964.

2. DAHNE, J. \& RAUPP, S. - Angiografia trans-operatória na cirurgia dos angiomas cerebrais. Atas do VI Congresso da Sociedade Brasileira de Neurocirurgia, São Paulo, 1966.

3. LOOF, W. J. \& FOLTZ, E. L. - Applications of angiography during intracranial operation. Acta Radiol. 5:363-367, 1966.

4. RAUPP, S. - Angiografia cerebral trans-operatória. Atas do VIII Congresso Nacional de Neurologia, Psiquiatria e Higiene Mental, Pôrto Alegre, 1967.

Instituto de Neurocirurgia - Hospital São Francisco - Pôrto Alegre — Rio Gíande do Sul, Brasil. 